\title{
Alteration of Sex and Non-Sex Hormones and Distribution Features of Blood ABO System Groups among the Women with Uterine Body Tumors
}

\author{
Irina Nakashidze' ${ }^{1}$ Anzor Diasamidze ${ }^{1}$, Davit Baratashvili', Marina Nagervadze1, \\ Manana Alibegashvili², Liana Ramishvili², Manana Gordeziani' ${ }^{2}$, Ana Khazaradze², \\ Nanuli Kotrikadze ${ }^{*}$ \\ ${ }^{1}$ Department of Biology, Faculty of Natural Sciences and Health Care, Batumi Shota Rustaveli State University, \\ Batumi, Georgia \\ ${ }^{2}$ Department of Biology, Faculty of Exact and Natural Sciences, Ivane Javakhishvili Tbilisi State University, Tbilisi, \\ Georgia \\ Email: $\underline{\text { nkotrikadze@gmail.com, nanuli.kotrikadze@tsu.ge }}$
}

Received 17 February 2014; revised 15 March 2014; accepted 22 March 2014

Copyright (C) 2014 by authors and Scientific Research Publishing Inc.

This work is licensed under the Creative Commons Attribution International License (CC BY). http://creativecommons.org/licenses/by/4.0/

(c) (i) Open Access

\section{Abstract}

Objectives: The aim of the investigation was to study the hormonal status (sex hormones: estradiol $\left(\mathrm{E}_{2}\right)$, progesterone $(\mathrm{P})$, testosterone $(\mathrm{T})$; non-sex gonadotropic hormones-luteinizing hormone ( $\left.\mathrm{LH}\right)$ and follicle-stimulating hormone (FSH)) of women with benign and malignant tumors of uterine body in the reproductive, menopause and postmenopause periods. Also the distribution features of the blood ABO system phenotype groups and their link to the development of uterine body tumors have been studied. Methods: The determination of hormones was made by the enzyme analysis method (ELAIZA), provided by the proper ELAIZA kits. For the study of blood ABO system antigens, internationally recognized immunoserology methods were used. Results: Investigations revealed the increased level of $E_{2}$ and $T$ on the background of the reduced $P$ in the blood of the women with uterine tumors in the reproductive, menopause and post-menopause period. As for gonadotropic hormones, the decreased levels of LH and FSH have also been detected. From the ABO system phenotype groups A(II) group had the highest frequency between the women with malignant uterine tumor in the reproductive age. $O$ (I) phenotype group was the most frequent in case of menopause and post-menopause women with uterine malignant tumors. Conclusions: Hormonal imbalance creates good conditions for the proliferation of uterine tissues and hence causes the development of benign and malignant uterine tumors. The imbalance of the sex steroid and gonadotropic hormones in the blood of post-menopause women indicates on the genotoxic

${ }^{*}$ Corresponding author. 
mechanism of cancer development on the background of age-related changes. A(II) group had the highest frequency between the reproductive age women with uterine malignant tumor, while 0 (I) group was the most frequent in case of menopause and post-menopause patients.

\section{Keywords}

\section{Uterine Body Tumors, Hormones, Benign Tumor, Malignant Tumor, Blood ABO System}

\section{Introduction}

The uterus is known to be the most sensitive organ towards hormones [1] [2]. Especially the effect of steroids on endometrial cells must be mentioned, since they regulate the normal functioning of female reproductive system [2]. Excess of estrogen (steroid hormone) induces the hyperplastic processes in uterine tissue and promotes formation of malignant or benign tumors of uterine body (mainly of myometrium and endometrium) [2]-[4]. As androgens are precursors of estrogens, their importance must also be mentioned. Increased secretion of androgens induces enhanced estrogenic stimulation of the uterus [5]. Here must be pointed out the influence of steroid hormones on synthesis and secretion of other hormones (gonadotropins) too [6].

It is well known that content of hormones in the blood of different age group women is diverse. Accordingly, mechanisms responsible for development of uterine body tumor in different age group women are not the same [7]. The tendency of uterine tumors rejuvenation must also be taken into account [2]. This fact points to the significance of studying the hormonal status in reproductive, also in menopause and post-menopause women.

Blood ABO system group antigens play a significant role in the functioning of immune system. Moreover they stimulate development of some malignant tumors [8]. Among them the tumors of woman's reproductive organs must be mentioned [9] [10]. According to the recent investigations there is an obvious relationship between the blood ABO system phenotype groups and formation of different tumors [11]-[19]. Therefore, it was significant to study the peculiarities of blood $\mathrm{ABO}$ system group distribution and establish their possible relation with uterine body tumors.

\section{Materials and Methods}

For the assesment of hormonal status the blood samples of reproductive (19 - 45 years), menopause (50 - 65 years) and post-menopause (65 - 75 years) women (from Adjara region, Georgia) with benign (fibroadenoma) and malignant tumors of uterine body had been used. Each study group (control group, benign tumor group, malignant tumor group) was consisted of 10 - 10 patients in case of each separate age group (reproductive, menopause or post-menopause) respectively. Each age group had relevant control group consisted from the women of same age. In case of reproductive age women blood samples were taken on day 20 of the regular cycle. The immunoenzyme method (ELAIZA) was used for hormone analysis.

Blood samples from the women with malignant tumors of uterine body were tested for investigation the ABO system antigens. The number of patients was 20 females for each study group (control group and malignant tumor group) from each separate age group. The same number of blood samples of healthy women served as control. The internationally acknowledged immunoserological methods were applied, while investigating the antigens of $\mathrm{ABO}$ system.

The study was approved by the ethics committee of Georgia and blood samples were collected with informed consent from patients. The investigations have been performed in 2012 - 2013 years.

Participants of the study were enrolled from Adjara Oncology Centre (Batumi). All the patients belonged to European (Caucasian) race.

Statistical analysis of experimental data were processed using the variance method, by means of computer program (Graphpad prisma 6) P < 0.05 was regarded as statistically significant.

\section{Results and Discussion}

The purpose of the study was to determine the hormonal status of reproductive, menopause and post-menopause age women with benign and malignant tumors of uterine body. The quantitative changes of steroid hormones- 
Estradiol $\left(\mathrm{E}_{2}\right)$, Progesterone (P) and Testosterone (T), also non-steroid gonadotropic luteinizing (LH) and follicle-stimulating (FSH) hormones were investigated.

According to our studies content of $E_{2}$ in the blood of reproductive age patients with uterine benign tumor was 1.3 times and in malignant cancer patients-2.3 times higher, compared with control (Table 1; Figure 1(a)). Value of $\mathrm{P}$ in case of benign tumor was 2.25 times and in case of malignant growth-3 times lower compared with the control group (Table 1; Figure 1(b)). While studying variation of $\mathrm{T}$ index, it was revealed that in reproductive age women with uterine body tumor its secretion diminished in both benign (1.3 times) and

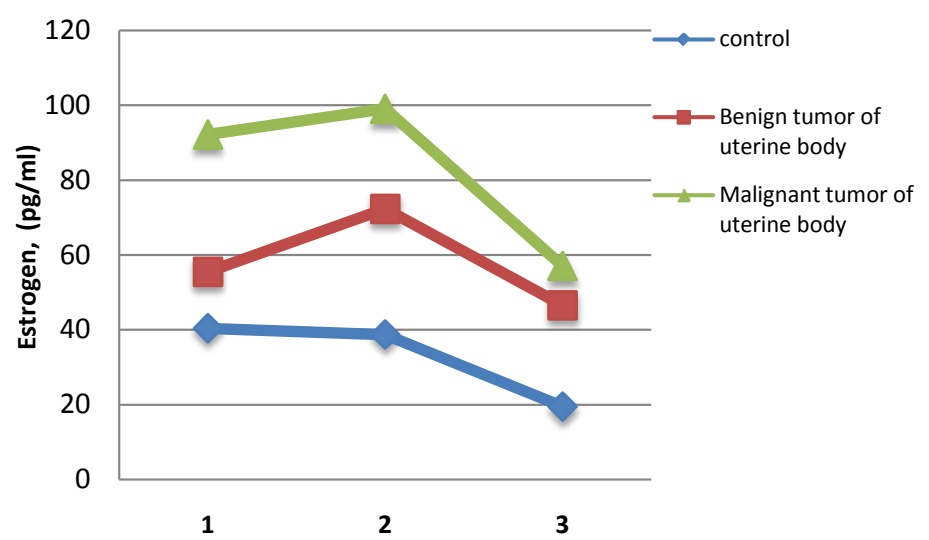

(a)

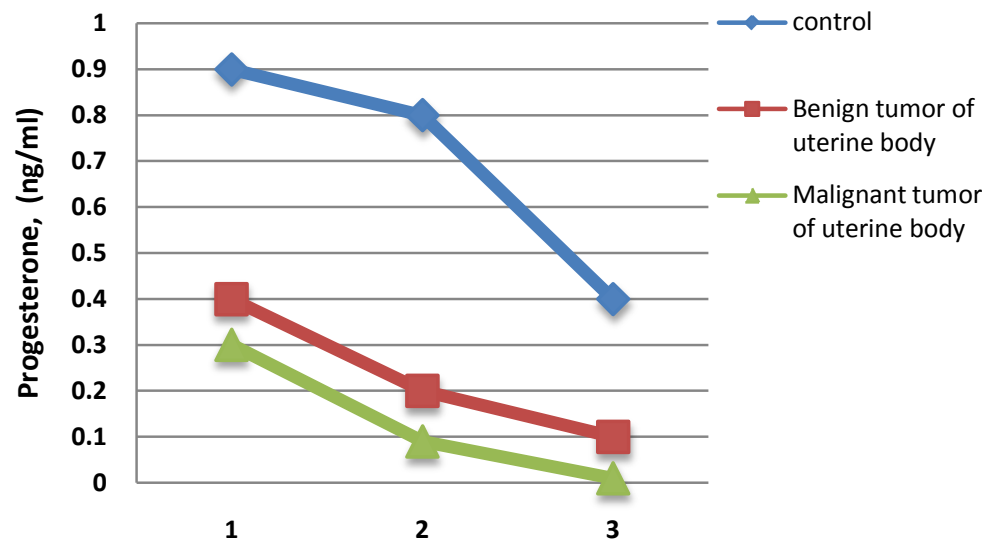

(b)

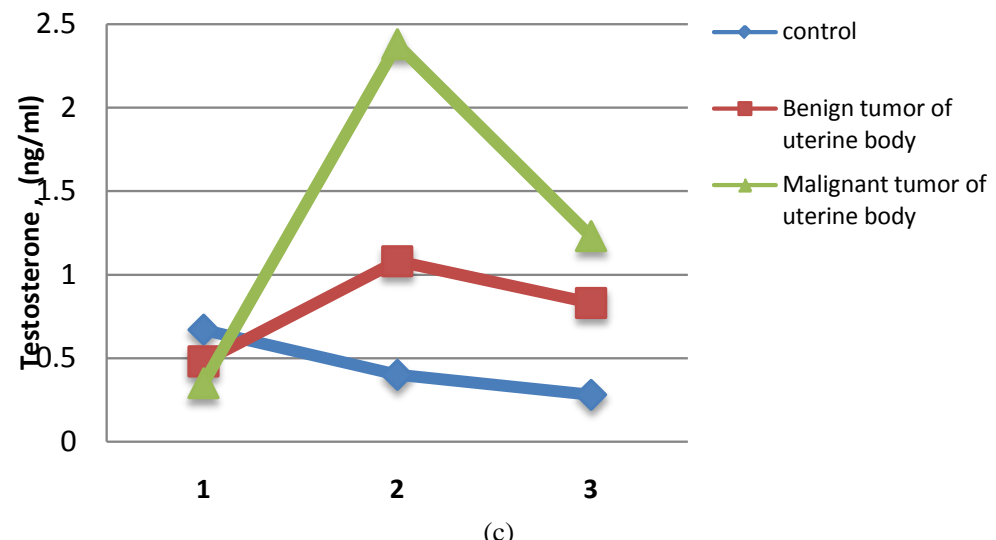

(c)

Figure 1. Example the quantitative changes of Estradiol; (a) Progesterone (b) and Testosterone (c) in the blood of women with uterine body tumors. 1 . Reproductive period; 2 . Menopause period; 3. Post-menopause period. 
Table 1. Alteration of steroid hormone levels in blood of women with uterine body tumors in reproductive, menopause and post-menopause periods.

\begin{tabular}{cccccccccc}
\hline \multirow{2}{*}{ Object } & \multicolumn{7}{c}{ Sex Steroid Hormones } \\
\cline { 2 - 10 } & \multicolumn{5}{c}{ Reproductive } & \multicolumn{3}{c}{ Menopause } \\
\hline & $\mathrm{E}_{2}(\mathrm{pg} / \mathrm{ml})$ & $\mathrm{P}(\mathrm{ng} / \mathrm{ml})$ & $\mathrm{T}(\mathrm{ng} / \mathrm{ml})$ & $\mathrm{E}_{2}(\mathrm{pg} / \mathrm{ml})$ & $\mathrm{P}(\mathrm{ng} / \mathrm{ml})$ & $\mathrm{T}(\mathrm{ng} / \mathrm{ml})$ & $\mathrm{E}_{2}(\mathrm{pg} / \mathrm{ml})$ & $\mathrm{P}(\mathrm{ng} / \mathrm{ml})$ & $\mathrm{T}(\mathrm{ng} / \mathrm{ml})$ \\
\hline Control & $40.4 \pm 0.4$ & $0.90 \pm 0.06$ & $0.67 \pm 0.009$ & $38.73 \pm 0.8$ & $0.83 \pm 0.017$ & $0.40 \pm 0001$ & $19.46 \pm 0.2$ & $0.42 \pm 0.017$ & $0.28 \pm 0.005$ \\
Benign & $55.5 \pm 0.03$ & $0.4 \pm 0.02$ & $0.48 \pm 0.004$ & $72.23 \pm 0.4$ & $0.22 \pm 0.009$ & $1.08 \pm 0.09$ & $46.55 \pm 0.9$ & $0.1 \pm 0.001$ & $0.83 \pm 0.006$ \\
tumor & $\mathrm{P}=0.001$ & $\mathrm{P}=0.001$ & $\mathrm{P}=0.007$ & $\mathrm{P}=0.0028$ & $\mathrm{P}=0.0001$ & $\mathrm{P}=0.0115 \mathrm{P}=0.016$ & $\mathrm{P}<0.001$ & $\mathrm{P}<0.003$ \\
Malignant & $95.2 \pm 0.8$ & $0.3 \pm 0.001$ & $0.35 \pm 0.008$ & $99.07 \pm 0.5$ & $0.09 \pm 0.006$ & $2.38 \pm 0.08$ & $57.08 \pm 0.2$ & $0.01 \pm 0.004$ & $1.23 \pm 0.01$ \\
tumor & $\mathrm{P}=0.0001$ & $\mathrm{P}=0.0001$ & $\mathrm{P}<0.001$ & $\mathrm{P}<0.0029$ & $\mathrm{P}=0.056$ & $\mathrm{P}=0.0022 \mathrm{P}<0.0001$ & $\mathrm{P}<0.002$ & $\mathrm{P}<0.001$ \\
\hline
\end{tabular}

$\mathrm{E}_{2}$-Estradiol; P-Progesterone; T-Testosterone; $\mathrm{n}=10$ (amount of patients in each group in case of each age group respectively); $\mathrm{P}<0.05$.

malignant growth (1.9 times) cases (Table 1; Figure 1(c)).

On the next step of investigations changes in the content of steroid hormones was studied in the blood of menopause age women with uterine cancer. It was revealed that amount of $E_{2}$ was increased in both benign and malignant growth cases (Table 1; Figure 2(a)), compared to the control group (1.3 and 2.5 times). As for P index, it decreased sharply by the following order: control group $\rightarrow$ benign tumor $\rightarrow$ malignant growth (Table 1; Figure 2(b)). It must be mentioned that on the background of evidently raised $\mathrm{E}_{2}$ and decreased $\mathrm{P}$, content of $\mathrm{T}$ was clearly increased in blood of patients with uterine benign tumor (2.7 times) and malignant tumor (5.95) as well (Table 1; Figure 2(c)).

The study of the blood of post-menopause women with uterine tumors has revealed that with aggravation of the disease amount of $E_{2}$ sharply increased (Table 1; Figure 3(a)) on the background of diminished P (Table 1; Figure 3(b)). As for T, its level rose in both groups of patients with uterine benign and malignant tumor (Table 1; Figure 3(c)).

It is well known that hypophysis regulates the synthesis of estrogens and progesterone in ovary by means of gonadotropic hormones [6]. Moreover, secretion of gonadotropic hormones is regulated by steroid hormones $\left(E_{2}\right.$, P) [20]. Accordingly, on the next step of investigations quantitative changes of non-steroid gonadotropic follicle-stimulating (FSH) and luteinizing (LH) hormones has been studied in the blood of reproductive, menopause and post-menopause age women for establishing the role of changes taking place in the system: hypophysis-ovary; hypophysis-adrenal gland, in formation of uterine benign and malignant tumors in above mentioned age groups.

According to the experimental results in the blood of reproductive age women with uterine benign or malignant tumors content of both FSH ( 2.2 fold) and LH increased (Table 2; Figure 1(a) and Figure 1(b)). In menopause age patients with uterine benign or malignant tumors rise of FSH and LH compared with control was also observed, like the reproductive age group (Table 2; Figure 1(b) and Figure 2(a)).

According to the gained results, in post-menopause women with the same diseases decrease of FSH was mentioned. As for LH, in the blood of patients with malignant tumor it remained almost the same, while in benign tumor patients amount of LH diminished (Table 2; Figure 3(a)).

Thus, quantitative studies of blood steroid hormones $\left(\mathrm{E}_{2}, \mathrm{P}, \mathrm{T}\right)$, gonadotropic-luteinizing $(\mathrm{LH})$ and folliclestimulating (FSH) hormones in the blood of reproductive, menopause and post-menopause age women with uterine benign and malignant tumors made possible to suppose that increase of estradiol in the blood of reproductive and menopause age patients with uterine benign tumor and its sharper gain in uterine malignant tumor patients (Figure 1 and Figure 2) may be stipulated by the functional condition of the reproductive system: inflammatory and infective processes, disorders in menstrual cycle, defective second phase in the menstrual cycle and undeveloped yellow body, low level of progesterone. Sharp increase of estradiol on the background of significant deficiency of progesterone may be responsible for the target organ-uterus tissues stimulation and formation of benign (fibromyoma, myoma) or malignant tumors in reproductive and menopause age women. As for increase of testosterone level in the blood of menopause and post-menopause patients with uterine benign or malignant tumors, this may be caused by the functional condition of the reproductive system, in particular, by the hyperplasia of ovary theca tissue, which, according to clinical data, is usual phenomenon in most patients. In addition to above mentioned, significant rise in testosterone content in menopause and post menopause age patients both with uterine benign or malignant tumors, may be the result of increased amount of androstendione 

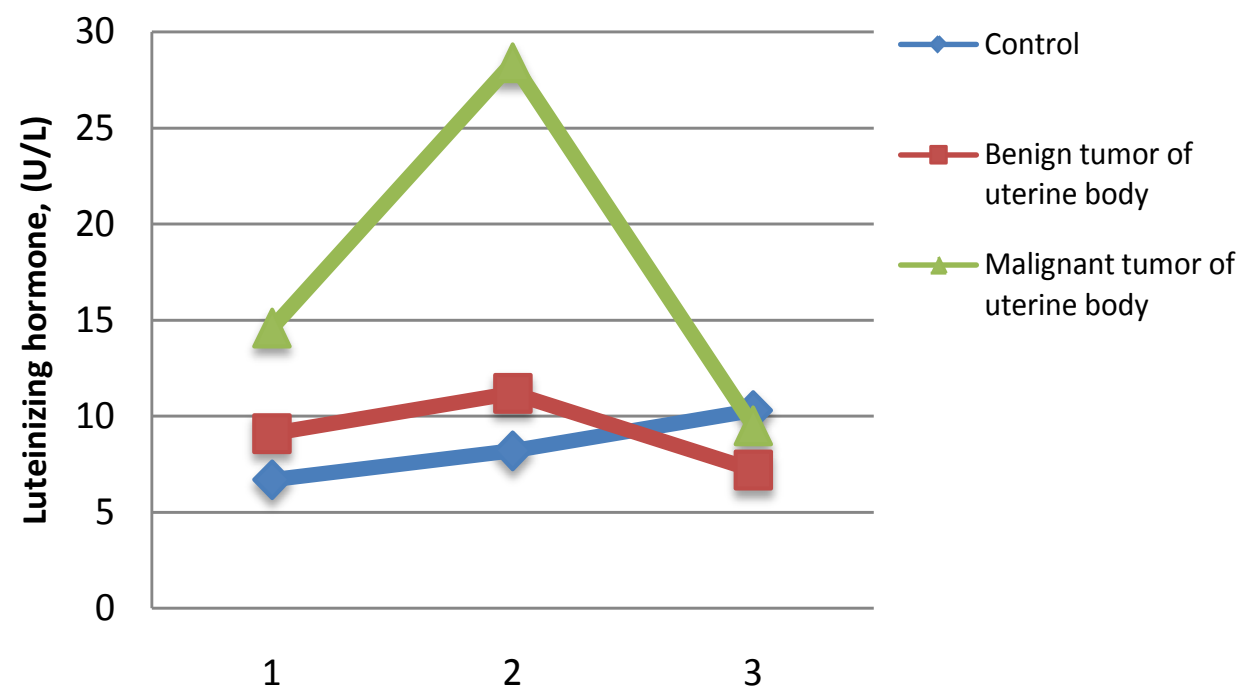

(a)

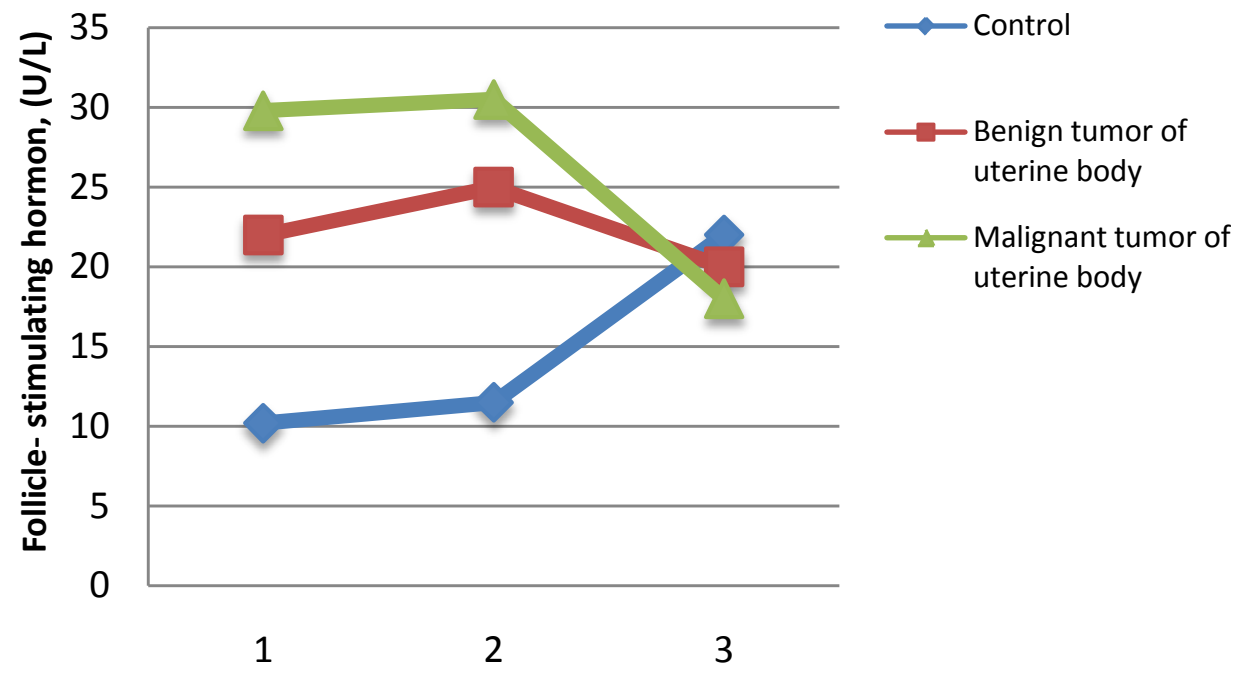

(b)

Figure 2. Example The quantitative changes of Luteinizing hormone (a) and Follicle-stimulating hormone (b) in the blood of women with uterine body tumors. 1. Reproductive period; 2 . Menopause period; 3. Post-menopause period.

Table 2. Alteration of gonadotropic hormones level in blood of women with uterine body tumors in reproductive, menopause and post-menopause periods

\begin{tabular}{ccccccc}
\hline \multirow{2}{*}{ Object } & \multicolumn{5}{c}{ Gonadotropic Hormones } \\
\cline { 2 - 7 } & \multicolumn{2}{c}{ Reproductive } & \multicolumn{2}{c}{ Menopause } & \multicolumn{2}{c}{ Post-menopause } \\
\cline { 2 - 7 } & $\mathrm{LH}(\mathrm{U} / \mathrm{L})$ & $\mathrm{FSH}(\mathrm{U} / \mathrm{L})$ & $\mathrm{LH}(\mathrm{U} / \mathrm{L})$ & $\mathrm{FSH}(\mathrm{U} / \mathrm{L})$ & $\mathrm{LH}(\mathrm{U} / \mathrm{L})$ & $\mathrm{FSH}(\mathrm{U} / \mathrm{L})$ \\
\hline \multirow{2}{*}{ Control } & $6.7 \pm 0.01$ & $10.2 \pm 0.05$ & $8.2 \pm 0.8$ & $11.05 \pm 0.3$ & $10.3 \pm 0.8$ & $22 \pm 0.4$ \\
& $9.1 \pm 0.05$ & $22 \pm 0.6$ & $11.2 \pm 0.5$ & $25 \pm 0.5$ & $7.2 \pm 0.05$ & $20 \pm 0.6$ \\
Benign tumor & $\mathrm{P}=0.007$ & $\mathrm{P}=0.0008$ & $\mathrm{P}=0.0008$ & $\mathrm{P}=0.001$ & $\mathrm{P}=0.0001$ & $\mathrm{P}<0.001$ \\
& $14.6 \pm 0.5$ & $29.8 \pm 0.05$ & $28.4 \pm 0.7$ & $30.5 \pm 0.8$ & $9.5 \pm 0.3$ & $18 \pm 0.7$ \\
Malignant tumor & $\mathrm{P}=0.006$ & $\mathrm{P}<0.003$ & $\mathrm{P}<0.016$ & $\mathrm{P}=0.0033$ & $\mathrm{P}=0.002$ & $\mathrm{P}<0.006$ \\
\hline
\end{tabular}

LH-luteinizing hormone; FSH-follicle-stimulating hormone; $\mathrm{n}=10$ (amount of patients in each group in case of each age group respectively); $\mathrm{P}<0.05$. 
(androgen) and its enhanced conversion (as the pre-hormone) into testosterone.

Concerning the quantitative changes of gonadotropic (luteinizing (LH)) and follicle-stimulating (FSH) hormones (Figure 2(a); Figure 2(b)) we suppose, that sharp gain of estradiol content in blood is in positive feedback relation with hypothalamus-hypophysis system and as a result, increase of follicle-stimulating (FSH) and luteinizing (LH) hormones takes place both in reproductive and menopause age women. Moreover, in little amounts progesterone increases the effect of estrogens and/or is responsible for intensification of gonadotropins secretion by the negative feed-back mechanism. Here must be mentioned that decreased level of FSH in postmenopause patients with uterine malignant tumor may be caused by the functional status of the reproductive system, by the diversity of histological forms of the tumor and its differentiation degree [2] [20].

Thus, investigations have revealed that changes in hypophysis-ovary system possess priority over the pathogenesis of uterine benign tumor in reproductive age, while in cases of malignant growth in menopause and postmenopause period changes in hypophysis-adrenal gland system play the major role. Above mentioned changes from its side, must have significant effect on the running of disease and its progression.

According to literary data there is a relation between blood groups and formation of different tumors [11]-[19]. The blood groups serve as prognostic markers in tumors investigation [21].

According to all above mentioned the purpose of our study was also to investigate the peculiarities of blood $\mathrm{ABO}$ system phenotypic groups distribution and their relation with the formation of uterine body tumors.

Four phenotypic groups (O(I), A(II), B(III), AB(IV)) were revealed in the blood of control as well as in blood of women with uterine malignant tumor in reproductive, menopause and post-menopause age.

In case of reproductive age women, $\mathrm{O}(\mathrm{I})$ group of the blood ABO system had the highest frequency of distribution among control group patients, while A(II) phenotypic group was most common in case of patients with malignant uterine body tumors. So uterine malignant growth may be associated with A(II) group. As for the B(III) group in control variants, its distribution was clearly limited compared with $\mathrm{O}(\mathrm{I})$ and A(II) phenotypic groups, but was twice higher in case of patients with uterine malignant tumor (Table 3; Figure 3).

All four phenotypic groups of the blood ABO system-O(I), A(II), B(III), AB(IV) were revealed among menopause age women with uterine malignant growth. $\mathrm{O}(\mathrm{I})$ phenotypic group had the highest index of distribution in control group (Table 3; Figure 3) and Distribution of A(II) phenotypic group was highest in patients with malignant uterine tumor. Comparatively low was the frequency of $\mathrm{B}(\mathrm{III})$ group. $\mathrm{AB}(\mathrm{IV})$ group was not found at all in menopause age women with uterine malignant growth (Table 3; Figure 3). Interesting results were received in control variants too. $\mathrm{O}(\mathrm{I})$ phenotypic group appeared to have the highest distribution here also. The second was $A(I I)$ phenotypic group, while frequency of distribution of $\mathrm{B}(\mathrm{II})$ and $\mathrm{AB}(\mathrm{IV})$ phenotypic groups of the blood ABO system were equally low (Table 3; Figure 3).

Investigations of post-menopause patients with uterine malignant tumor revealed the highest extent of distribution of $\mathrm{O}(\mathrm{I})$ phenotypic group. Quite high was distribution of A(II) phenotypic group too (Table 3; Figure 3). $\mathrm{B}(\mathrm{III})$ and $\mathrm{AB}(\mathrm{IV})$ phenotypic groups were clearly low in uterine malignant tumor patients, while in control group of post-menopause women $\mathrm{B}(\mathrm{III})$ phenotypic group of blood $\mathrm{ABO}$ system was sharply low, and $\mathrm{AB}(\mathrm{IV})$ group was not identified at all. The dynamic of distribution of O(I) and A(II) phenotypic groups in the control variants of post-menopause women was the same as in uterine malignant tumor patients (Table 3; Figure 3).

Table 3. Distribution characteristics of blood ABO system groups in blood of women with uterine body tumors in reproductive, menopause and post-menopause periods.

\begin{tabular}{|c|c|c|c|c|c|c|}
\hline \multirow{2}{*}{$\begin{array}{c}\text { Phenotype groups of } \\
\text { ABO system }\end{array}$} & \multicolumn{2}{|c|}{ Reproductive } & \multicolumn{2}{|c|}{ Menopause } & \multicolumn{2}{|c|}{ Post-menopause } \\
\hline & control & $\begin{array}{c}\text { malignant } \\
\text { tumor }\end{array}$ & control & $\begin{array}{c}\text { malignant } \\
\text { tumor }\end{array}$ & control & $\begin{array}{c}\text { malignant } \\
\text { tumor }\end{array}$ \\
\hline 0 (I) & $60 \% \pm 10.6 \%$ & $20 \% \pm 8.9 \%$ & $65 \% \pm 10.6 \%$ & $55 \% \pm 11.1 \%$ & $55 \% \pm 11.1 \%$ & $60 \% \pm 10.9 \%$ \\
\hline A (II) & $30 \% \pm 10.2 \%$ & $65 \% \pm 10.6 \%$ & $25 \% \pm 10.2 \%$ & $40 \% \pm 10.6 \%$ & $40 \% \pm 10.2 \%$ & $30 \% \pm 10.6 \%$ \\
\hline B (III) & $5 \% \pm 4.8 \%$ & $10 \% \pm 6.7 \%$ & $5 \% \pm 4.8 \%$ & $5 \% \pm 4.8 \%$ & $5 \% \pm 4.8 \%$ & $5 \% \pm 4.8 \%$ \\
\hline AB (IV) & $5 \% \pm 4.87 \%$ & $5 \% \pm 4.8 \%$ & $5 \% \pm 4.8 \%$ & $0 \% \pm 0 \%$ & $0 \% \pm 0 \%$ & $5 \% \pm 4.8 \%$ \\
\hline
\end{tabular}

$\mathrm{n}=20$ (amount of patients in each group in case of each age group respectively); $\mathrm{P}<0.05$. 


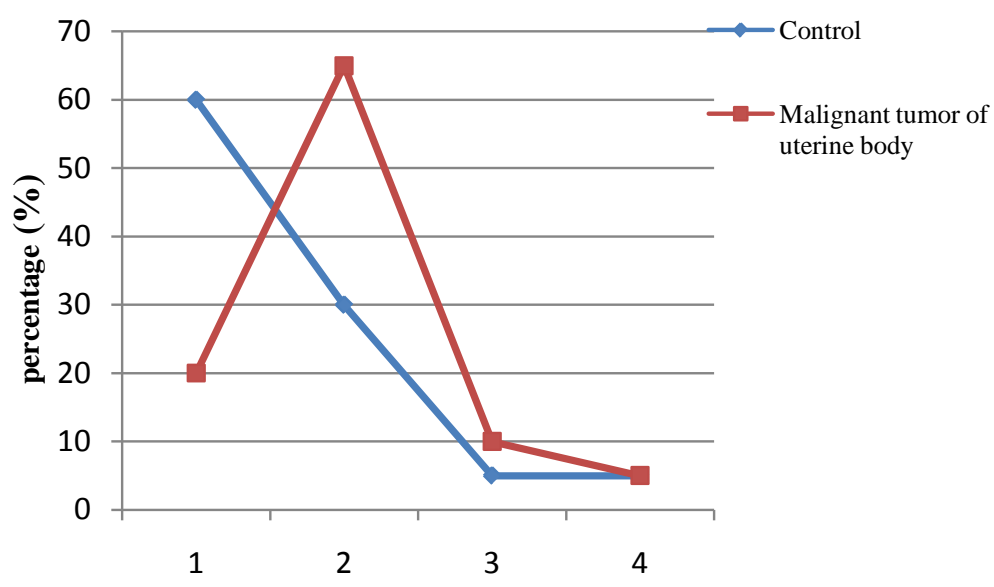

(a)

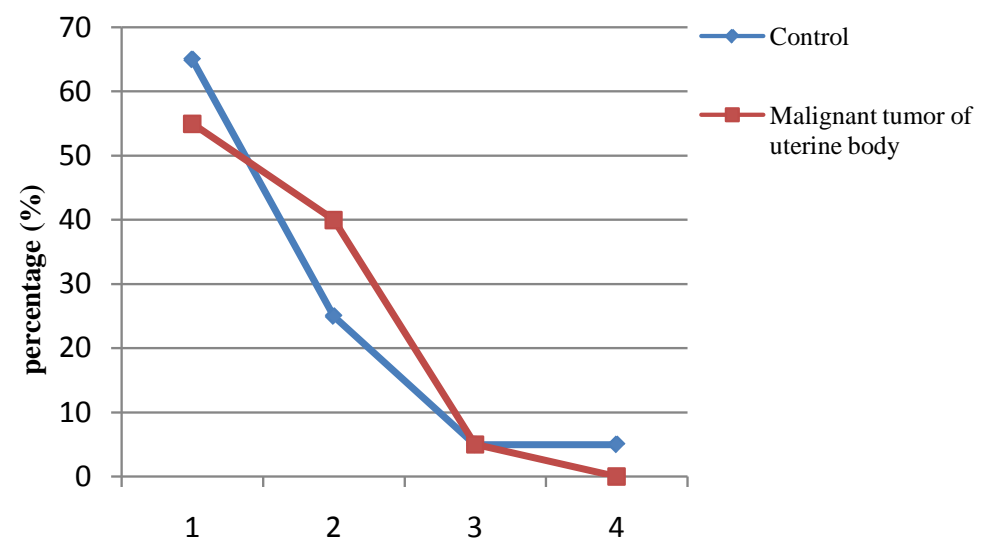

(b)

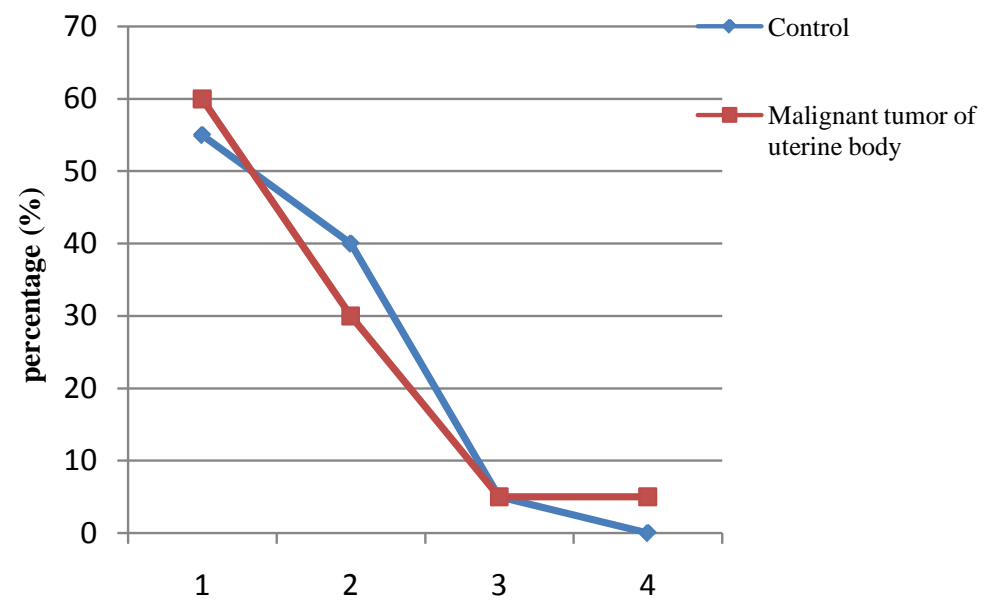

(c)

Figure 3. Distribution frequencies of blood ABO system phenotype groups in the blood of women with uterine body tumors. 1-O(I); 2-A(II); 3-B(III); 4AB(IV). (a) Reproductive period; (b) Menopause period; (c) Post-menopause period.

\section{Conclusions}

Thus, a wide spectrum of hormonal imbalances has been revealed in patients with benign and malignant tumor of uterine body in case of reproductive, menopause as well as in case of post-menopause age group. However, 
these changes were the most prominent in case of malignant tumor. Hormonal imbalance creates good conditions for the proliferation of uterine tissues and hence contributes to the development of benign and malignant uterine tumors.

Investigations have revealed that in reproductive age patients changes in hypophysis-ovary system possess priority in the pathogenesis of uterine benign and malignant tumor, while in cases of malignant growth in menopause and post-menopause period changes in hypophysis-adrenal gland system play the major role. Above mentioned changes from its side, must have a significant effect on the running of disease and its progression.

The imbalance of the sex steroid and gonadotropic hormones (Decreased level of Progesterone, Increased level of sex hormones and reduced gonadotropic hormones) in the blood of post-menopause women indicates the genotoxic mechanism of cancer development on the background of age-related changes.

From the ABO system phenotypic groups A(II) group had the highest prevalence among the reproductive age women with malignant uterine body tumors, while in the blood of menopause and post-menopause age patients, $\mathrm{O}$ (I) phenotypic group was the most common.

\section{References}

[1] Menasce, L.P., White, G.R., Harrison, C.J. and Boyle, J.M. (1993) Localization of the Estrogen Receptor Locus (ESR) to Chromosome 6q25.1 by FISH and a Simple Post-FISH Banding Technique. Journal of Genomics, 17, $263-265$. http://dx.doi.org/10.1006/geno.1993.1320

[2] Bender, D., Thomas, B. and Leslie, K. (2011) Hormones and Receptors in Endometrial Cancer. Proceedings in Obstetrics and Gynecology, 2, 1-25.

[3] Bershtein, L.M. (2000) Hormonal Carcinogenesis. SPB. Nauka. 64-73.

[4] Henderson, B.E. and Feigelson, H.S. (2000) Hormonal Carcinogenesis. Carcinogenesis, 21, 427-433. http://dx.doi.org/10.1093/carcin/21.3.427

[5] Ovsyanikova, T.V., Speranskaya, N.V., et al. (2000) Androgens in Physiology and Patho-Physiology of Women’s Organism. Gynecology, 2, 2.

[6] Laycock, F.J. and Wise, H.P. (1996) Essential Endocrinology. Oxford University Press, Oxford. http://trove.nla.gov.au/work/11667680

[7] Hale, G.E., Hughes, C.L. and Cline, J.M. (2002) Endometrial Cancer: Hormonal Factors, the Perimenopausal "Window of Risk,” and Isoflavones. Journal of Clinical Endocrinology and Metabolism, 87, 3-15.

[8] Stamatakos, M., Kontzoglou, K., Safioles, P., Safioles, C., Manti, C. and Safioles, M. (2009) Breast Cancer Incidence in Greek Women in Relation to ABO Blood Groups and Rh Factor. Journal of International Seminars in Surgical Oncology, 16, 1-15.

[9] Adamian, R.T. (2005) Blood Type and Rhesus Distribution in Armenian Women with Endometrial Carcinoma. Voprosy Onkologii, 51, 575-576.

[10] Wolpin, M.B., Chain, A.T., Hartge, P., Stephen, C., Kraft, J.P., Hunter, D.H., et al. (2009) ABO Blood Groups and the Risk of Pancreatic Cancer. Journal of National Cancer Institute, 10, 424-431. http://dx.doi.org/10.1093/jnci/djp020

[11] Garrety, G. (2005) Do We Need to Be More Concerned about Weak D Antigens? Journal of Transfusion, 45, 15471551. http://dx.doi.org/10.1111/j.1537-2995.2005.00625.X

[12] Jovanovic-Cupic, S., Stamencovic, G., Blagojevic, J., Vanis, N., Stanojevic, B. and Berberovic, L.J. (2008) ABO Histo-Blood Groups and Rh Systems in Relation to Malignant Tumors of the Digestive Tract in Bosnia and Herzegovenia. Journal of Archives of Biological Sciences, 60, 593-599. http://dx.doi.org/10.2298/ABS0804593J

[13] Amundadottir, L., Kraft, P., Stolzenberg-Solomon, R.Z., Fuchs, C.S., Petersen, G.M., Arslan, A.A., et al. (2009) Genome-Wide Association Study Identifies Variants in the ABO Locus Associated with Susceptibility to Pancreatic Cancer. Journal of Nature Genetics, 41, 986-990. http://dx.doi.org/10.1038/ng.429

[14] Bayan, K., Tuzun, Y., Yilmaz, S., Dursun, M. and Canoruc, F. (2009) Clarifying the Relationship between ABO/Rhesus Blood Group Antigens Upper and Gastrointestinal Bleeding. Journal of Digestive Diseases and Sciences, 54, 1029-1034. http://dx.doi.org/10.1007/s10620-008-0446-0

[15] Anestee, D.J. (2010) The Relationship between Blood Groups And Disease. Journal of Blood, 15, 4635-4643. http://dx.doi.org/10.1182/blood-2010-01-261859

[16] Edgren, G., Hjalgrim, H., Rostgaard, K., Norda, R., Wikman, A., et al. (2010) Risk of Gastric Cancer and Peptic Ulcers in Relation to ABO Blood Type: A Cohort Study. American Journal of Epidemiology, 172, 1280-1285. http://dx.doi.org/10.1093/aje/kwq299

[17] Greer, J.B., Yazer, M.H., Raval, J.S., Barmada, M.M., Brand, R.E. and Whitcomb, D.C. (2010) Significant Association 
between ABO Blood Group and Pancreatic Cancer. World Journal of Gastroenterol, 16, 5588-5591. http://dx.doi.org/10.3748/wjg.v16.i44.5588

[18] Qiu, M.Z., Zhang, D.S., Ruan, D.Y., Luo, H.Y., Wang, Z., et al. (2010) A Relationship Between ABO Blood Groups and Clinicopathologic Characteristics of Patients with Gastric Adenocarcinoma in China. Journal of Medical Oncology, 28, S268-S273. http://dx.doi.org/10.1007/s12032-010-9735-5

[19] Gates, M.A., Xu, M., Chen, W.Y., Kraft, P., Hankinson, S.E. and Wolpin, B.M. (2012) ABO Blood Group and Breast Cancer Incidence and Survival. International Journal of Cancer, 130, 2129-2137. http://dx.doi.org/10.1002/ijc.26220

[20] Tupinashvili, T. (2006) The Study of Blood Lipid and Protein Spectrum in Case of Hormonal Imbalance during Uterine Body Tumors. Ph.D. Dissertation, Ivane Javakhishvili Tbilisi State University, Tbilisi.

[21] Costantini, M., Fassio, T., Canobbioet, L., Landucci, M., Resasco, M. and Boccardo, F. (1990) Role of Blood Groups as Prognostic Factors in Primary Breast Cancer. Journal of Oncology, 47, 308-312. http://dx.doi.org/10.1159/000226839 